\title{
An atypical large ulcero-budding type nodular fasciitis of the hand: a case report
}

\section{Study performed at the University Hospital of Bobo-Dioulasso (Burkina Faso)}

\author{
M Diallo, ${ }^{1}$ PWH Dakouré, ${ }^{2}$ V Konségré, ${ }^{3}$ M Soulama, ${ }^{4}$ S Gandéma ${ }^{5}$
}

MD, Lecturer in Orthopaedics and Trauma Surgery, University Hospital of Bobo-Dioulasso (Burkina Faso)

MD FWACS, Associate Professor in Orthopaedics and Trauma Surgery; Head of Orthopaedics and Trauma Surgery Department, University Hospital of Bobo-Dioulasso (Burkina Faso)

MD, Lecturer in Anatomopathology, University Hospital of Bobo-Dioulasso (Burkina Faso)

4 Orthopedist and Trauma Surgeon, University Hospital of Bobo-Dioulasso (Burkina Faso)

MD, Senior lecturer in Physical Medicine, University Hospital of Bobo-Dioulasso (Burkina Faso)

Corresponding author: Dr Malick Diallo, Email: malikijallo@yahoo.com, malick.diallo@univ-bobo.bf, Mobile: +226 65193236

\begin{abstract}
Background: Nodular fasciitis is a benign soft-tissue tumour mimicking a sarcoma. It is generally subcutaneous and small in size. Case presentation: The authors report an exceptional case of a large ulcero-budding proliferative nodular fasciitis located on the hand of a 15-year-old boy.
\end{abstract}

Conclusion: This exceptional case focused on the effect of repetitive microtrauma on a nodular fasciitis.

Key words: nodular fasciitis, proliferative, hand, witchdoctors, large

Citation: Diallo M, Dakouré PWH, Konségré V, Soulama M, Gandéma S. An atypical large ulcero-budding type nodular fasciitis of the hand: A case report. SAOJ 2017;16(3):74-76. DOI 10.17159/2309-8309/2017/v16n3a11

Editor: Prof Anton Schepers, University of the Witwatersrand

Received: August 2016 Accepted: January 2017 Published: August 2017

Copyright: (c) 2017 Diallo M, et al. This is an open-access article distributed under the terms of the Creative Commons Attribution Licence, which permits unrestricted use, distribution and reproduction in any medium, provided the original author and source are credited.

Funding: No funding was received for the purposes of this case study.

Conflict of interest: The authors declare that they have no competing interests in the publication of this case study.

\section{Background}

Nodular fasciitis (NF), also known as subcutaneous pseudosarcomatous fibromatosis, ${ }^{1}$ pseudosarcomatous fasciitis, ${ }^{2}$ and infiltrative fasciitis, ${ }^{3}$ is a benign soft-tissue tumour.

This subcutaneous tumour, around 2 to $5 \mathrm{~cm}$ in size, ${ }^{1,2}$ often mimics malignant tumours, ${ }^{1,4}$ and rarely recurs. ${ }^{2}$ According to our knowledge and research, no case of an ulcero-budding clinical aspect or a large NF has previously been described in the literature.

We report the case of a 15-year-old boy who presented with a recurrence of a large ulcero-budding tumour on the dorsal aspect of his right hand. A large excision with skin graft was performed with a good outcome after two years.

\section{Case presentation}

A 15-year-old, right-handed schoolboy presented initially with a large ulcero-budding tumefaction on his right hand. His history referred to a year before when he had a minimal trauma to the dorsal aspect of his hand, followed by a small painless tumefaction which increased quickly over two weeks to $10 \mathrm{~mm}$ in diameter. The tumour was excised under local anaesthesia in a small hospital without any associated histological study. After the primary surgery, the patient's parents took him to see witchdoctors. They performed scarifications, and applied unidentified topical mixtures to the lesion. The surgical site never healed, and the tumefaction became larger, budding and ulcerous over two months. 
Because of the great difficulty he had in using his right hand, he left school. Later, his parents were convinced to bring him to hospital. At admission, clinical findings revealed he was in good physical condition, other than a large oval-shaped, foul, budding and ulcerous tumour around $14 \mathrm{~cm}$ in diameter on the dorsum of his hand, with a loss of flexion of the long fingers (Figure 1). There were no peripheral associated adenopathies.

The anteroposterior (AP) and lateral radiographs views of the hand showed an enlargement of soft tissues without any osseous lesion (Figure 2). CT scan was not performed. Clinical and radiographical extension checking did not find any metastasis.

Under general anaesthesia and tourniquet, extensive monobloc excision of the tumour was undertaken. The decision to follow the surgical route was due, at the time of the surgery, to the lack of a histologist in the hospital, and to the suspicion of a sarcoma. The excised tumour weighed $560 \mathrm{~g}$ and was adherent to fascia, extensor tendons and the posterior capsule of the wrist joint. A homologous split-skin graft from the right thigh was used to cover the surgical site. The histology results, available four months after surgery, showed a proliferative type of NF (Figures 3 and 4). The post-operative period was uneventful and the graft healed in three weeks. Two months of physical rehabilitation followed. It was not possible to perform immunostains.

Two years after surgery, there was no new recurrence; the dorsal skin was sensitive and the function good. The hand was painless, sensitive, and supple with 45 degrees of loss of active extensions of the four long fingers (Figure 5).

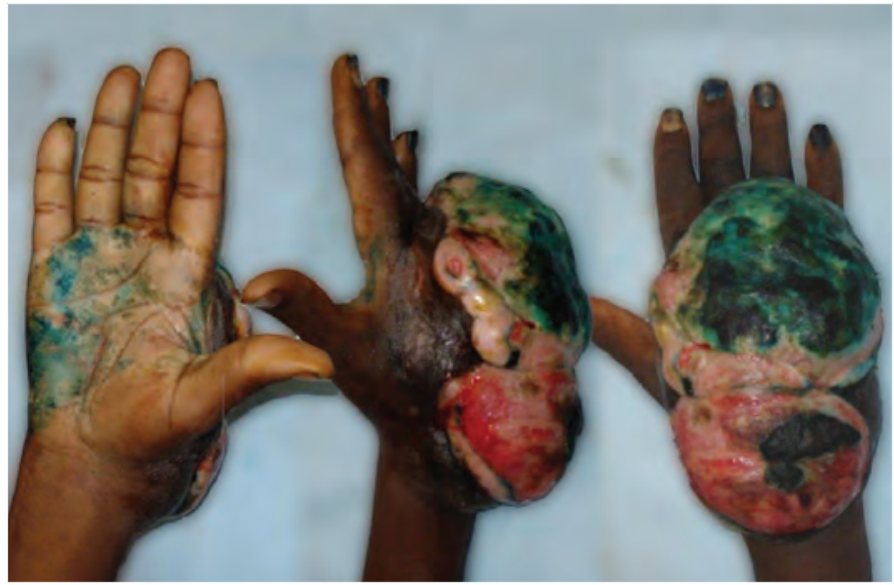

Figure 1. Condition of the right hand at admission

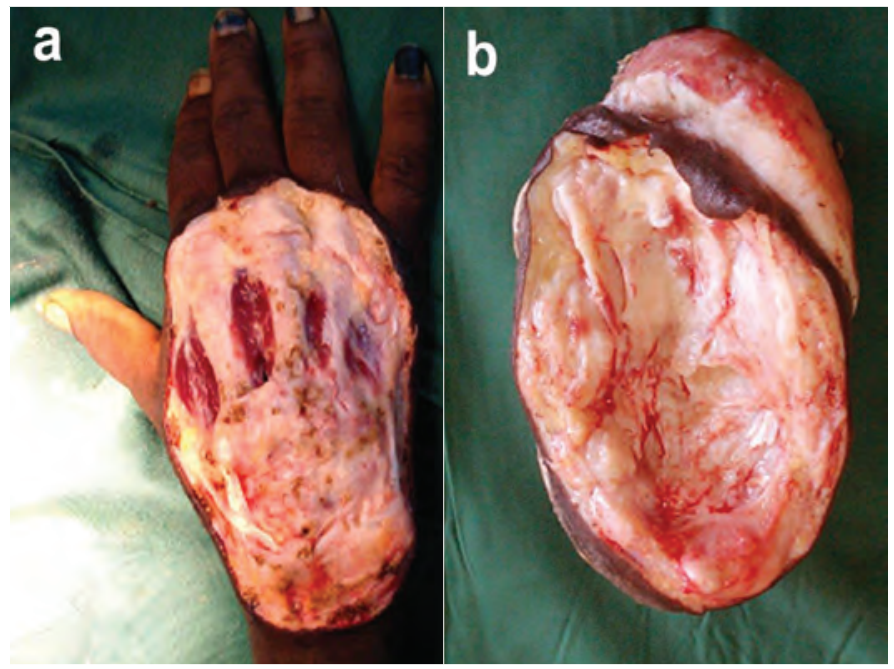

Figure 2. A large posterior oval-shaped tumour containing extensor tendons and the wrist posterior capsule (Figure 2b) was removed from the dorsal aspect of the right hand (Figure $2 \mathrm{a}$ )

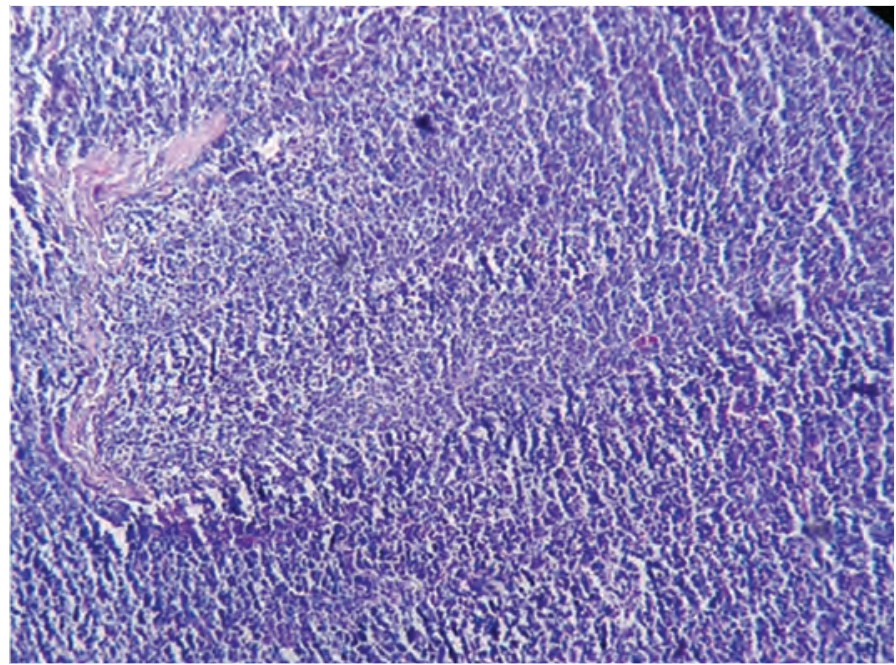

Figure 3. Nodular fasciitis with cellular proliferation in a fibrous collagen stroma (HES $\times 100)$

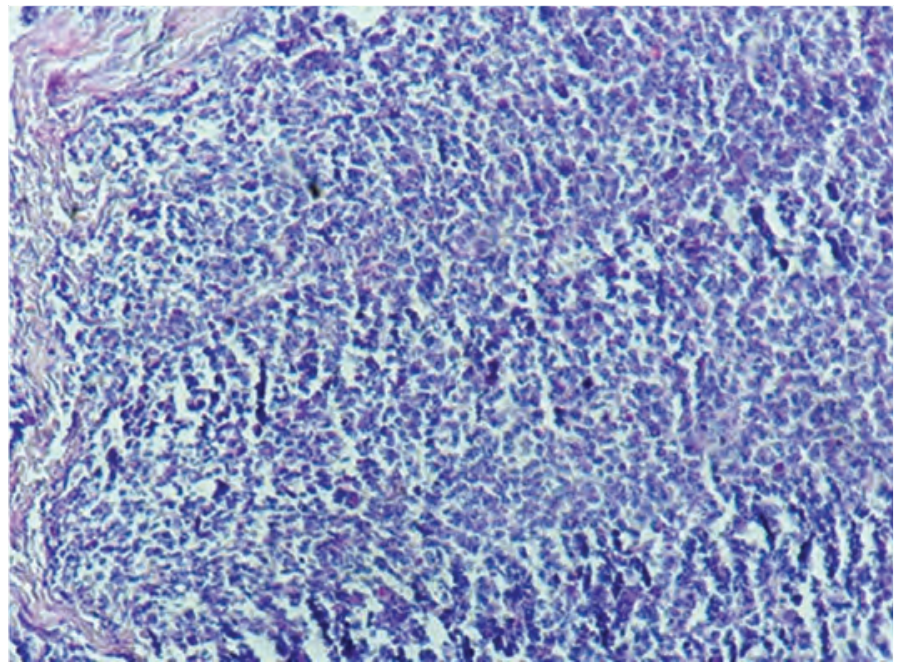

Figure 4. Spindle-shaped cells with a mitotic activity $(H E S \times 200)$

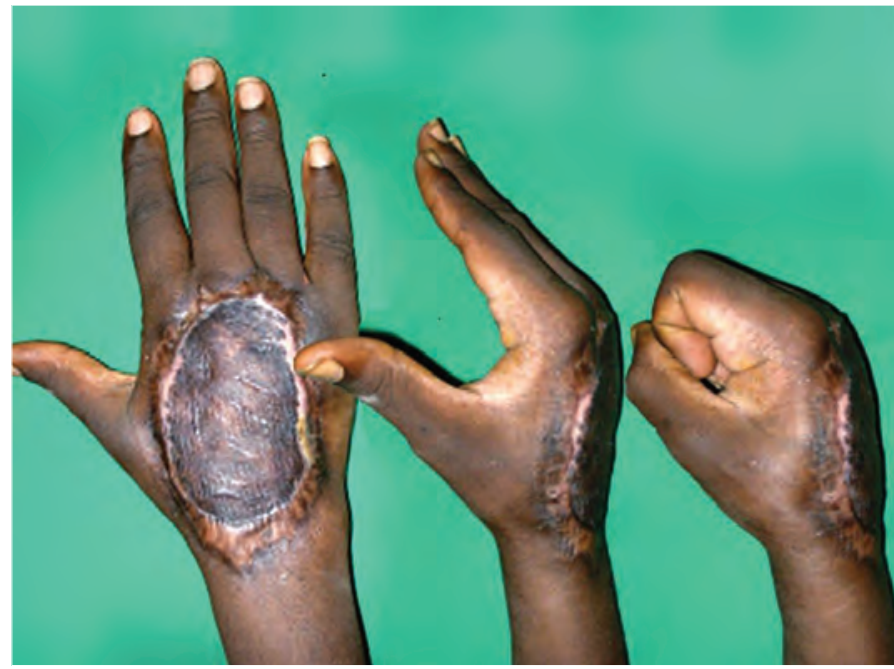

Figure 5. Range of mobility of the right hand after two years 


\section{Discussion}

\section{Clinical findings}

$\mathrm{NF}$ is a benign, fast-growing lesion that occurs frequently in the first three decades of life. ${ }^{2,4}$

It is located anywhere on the body, from the forearm, 2,5 to the thigh, ${ }^{5}$ the arm and face,,$^{6,7}$ the trunk, ${ }^{2}$ etc. Lesions in the hand, however, are rare. ${ }^{8,9}$ Exceptional intraneural NF has being reported..$^{10}$

A history of trauma at the tumoral site is often reported. ${ }^{2}$ Symptoms on the upper extremity are occasional pain, ${ }^{2}$ paraesthesia, ${ }^{11}$ tenderness ${ }^{12}$ and loss of motion. The lesion is typically solitary and small, around 10 to $30 \mathrm{~mm}$ in diameter. 2,5 Some authors report a slightly larger lesion. ${ }^{11}$ A typical variant of an NF is subcutaneous ${ }^{13}$, but rarely intra-dermal or intravascular. ${ }^{14,15}$ The lesion size of the current case was probably due to the repetitive micro-traumas of scarifications, topical mixtures and delayed care. These may also explain the ulcerous and budding aspects of the lesion.

\section{Histological features}

Histologically, NF appears like reparative tissue, with atypical granulation tissue. It is composed of numerous randomised spindle cells in a fibrous or a myxoid stroma with high mitotic index. ${ }^{2,6}$ The three major types of NF are myxoid, fibrous and cellular NF. ${ }^{5}$ Many benign and malignant lesions might mimic $\mathrm{NF}^{2}$ In the current case, histology showed proliferative spindle-shaped cells with some mitotic activity in a fibrous stroma. Immunohistology found positive fibroblasts/myofibroblasts stains ${ }^{16}$ and many negative stains (S100, CD34, keratin, etc.). ${ }^{17}$

\section{Management}

Misdiagnosis of an NF can lead to amputation. ${ }^{9}$ The mean time to care is two months. ${ }^{2}$ Some authors prefer to use fine-needle aspiration; ${ }^{18}$ others recommend excisional biopsy. ${ }^{2,19}$ Rare cases of successful treatment with ibuprofen ${ }^{11}$ and intralesional corticosteroids injections ${ }^{20}$ are reported.

It is our opinion that conservative treatment may be indicated for normal-sized NF and surgery for larger NF. In our hospital practice, histological results are delayed and many patients do not return for follow-up; we therefore opt to perform surgery.

\section{Recurrence}

Recurrences of an NF are discussed in the literature, with many authors assuming that it is impossible, even if the primary excision is incomplete. ${ }^{4}$ Bernstein ${ }^{2}$ reviewed 18 recurrences in 134 patients with an original NF diagnosis. He found only one possible case with primary and recurrence compatibility with NF. In the absence of primary histological study, it is difficult to know the nature of our patient's primary tumour.

\section{Conclusion}

The clinical aspect of the case under discussion was highly compatible with a soft-tissue sarcoma. Our decision to perform a large excision was justified by the clinical aspect and the histological study delay. We concluded that the size and the ulcerous aspect of this NF were due to repetitive micro-traumas and pro-inflammatory unidentified substances used by the witchdoctors.

\section{General ethical considerations and consent}

All patient data has been de-identified. The study did not require ethical approval according to the standards of the institution in which it was carried out.

The patient and his parents were informed that data concerning the case would be submitted for publication. He agreed to this. He granted permission to use photographs.

\section{Acknowledgements}

The authors thank Dr Robert Bobilwendé Sakandé and Dr Tim Keenan for their help.

\section{References}

1. Konwaler B, Keasbey L, Kaplan L. Subcutaneous pseudosarcomatous fibromatosis (fasciitis). American Journal of Clinical Pathology. 1955;25:241.

2. Bernstein KE, Lattes R. Nodular (pseudosarcomatous) fasciitis, a nonrecurrent lesion: Clinicopathologic study of 134 cases. Cancer. 1982;49:1668-78.

3. Sherwin R, Friedell G. Pseudosarcomatous fibromatosis (infiltrative fasciitis): report of two cases. BMQ; the Boston Medical Quarterly. 1959;10:49-51.

4. Dijoux P, Mesturoux L, Charissoux A, Pommepuy I, Layre B, Marcheix PS. [Nodular fasciitis: case report and review of the literature]. Chir Main. 2013;32:341-44

5. Shimizu S, Hashimoto H, Enjoji M. Nodular fasciitis: An analysis of 250 patients. Pathology. 1984;16:161-66.

6. Naidu A, Lerman MA. Clinical pathologic conference case 3: nodular fasciitis. Head and Neck Pathology. 2011;5:276-80.

7. Wiart T, Lebas D, Gosset P, Modiano P. Fasciite nodulaire: trois cas Annales de dermatologie et de venereologie. 2012;139:B233.

8. Sailon AM, Cappuccino G, Hameed M, Fleegler EJ. Nodular fasciitis of the hand over the metacarpophalangeal joint: a case report. Eplasty. 2008;8.

9. McCarthy EF, Ireland DC, Sprague BL, Bonfiglio M. Parosteal (nodular) fasciitis of the hand. A case report. J Bone Joint Surg. 1976;58: 714-16.

10. Mahon JH, Folpe AW, Ferlic RJ. Intraneural nodular fasciitis: case report and literature review1. Journal of Hand Surgery. 2004;29:148-53.

11. Duncan SFM, Athanasian EA, Antonescu CR, Roberts CC. Resolution of nodular fasciitis in the upper arm. Radiology Case Reports. 2006;1:17-20.

12. Mehregan AH. Nodular fasciitis. Archives of Dermatology. 1966;93 204-10.

13. Leung L, Shu S, Chan A, Chan M, Chan C. Nodular fasciitis: MR appearance and literature review. Skeletal Radiology. 2001;31:9-13.

14. Freedman PD, Lumerman $\mathrm{H}$. Intravascular fasciitis: report of two cases and review of the literature. Oral surgery, Oral Medicine, Oral Pathology. 1986;62:549-54.

15. Price SK, Kahn LB, Saxe N. Unusual variants of nodular fasciitis. The American Journal of Dermatopathology. 1993;15.

16. Perez-Montiel M, Plaza J, Dominguez-Malagon H, Suster S. Differential expression of smooth muscle myosin, smooth muscle actin, $\mathrm{h}$-caldesmon, and calponin in the diagnosis of myofibroblastic and smooth muscle lesions of skin and soft tissue. Am J Dermatopathol. 2006;28:105-11.

17. Weiss S and Nickoloff B. CD-34 is expressed by a distinctive cell population in peripheral nerve, nerve sheath tumors, and related lesions. The American Journal of Surgical Pathology. 1993;17:1039-45.

18. Stanley MW, Skoog L, Tani EM, Horwitz CA. Nodular fasciitis: Spontaneous resolution following diagnosis by fine-needle aspiration. Diagnostic cytopathology. 1993;9:322-24.

19. Kijima H, Okada K, Ito H, Shimada $Y$, Nanjo H, Itoi E. Nodular fasciitis of the finger. Skeletal Radiology. 2004;34:121-23.

20. Graham BS, Barrett TL, Goltz RW. Nodular fasciitis: Response to intralesional corticosteroids. Journal of the American Academy of Dermatology. 1999;40:490-92. 